\title{
Taming the Fontan with the Y-graft: A nod and a wink to the great Yu
}

Tain-Yen Hsia, MD

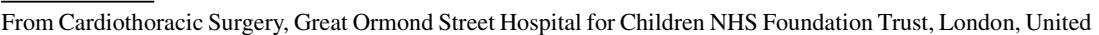
Kingdom.

T-Y.H. is the Principle Investigator of a Transatlantic Network of Excellence grant from Fondation Leducq, Paris, France.

Disclosures: Author has nothing to disclose with regard to commercial support.

Received for publication March 18, 2016; accepted for publication March 18, 2016.

Address for reprints: Tain-Yen Hsia, MD, Cardiac Unit 7th Floor, Nurses Home Great Ormond St Hospital for Children, NHS Foundation Trust, London, UK WC1N 3JH (E-mail: hsiat@gosh.nhs.uk).

J Thorac Cardiovasc Surg 2016;151:1537-9

$0022-5223 / \$ 36.00$

Copyright (C) 2016 by The American Association for Thoracic Surgery

http://dx.doi.org/10.1016/j.jtcvs.2016.03.027
}

According to ancient historical accounts, such as the Records of the Grand Historian (史記) written between 109 BC and 91 BC and the Bamboo Annals (竹書紀年), a man named Yu the Great (大禹) was a legendary ruler in ancient China between 2200 and 2010 BC (Figure 1). During this period, catastrophic floods from the Yellow River that prevented economic and social development frequently plagued the primordial Chinese heartland. Legends have it that Yu's father Gun was given the task of controlling the Yellow River floods. However, his 9-year effort of building a series of dikes and dams was ineffective, and Gun was executed. As an adult, Yu was tasked with continuation of his father's work. After careful investigations and field studies, instead of carrying on with his father's "blocking" strategy, over a 13-year period, he not only tamed the raging Yellow River through series of Y-like diversions into smaller rivers and canals but also created the 9 provinces (Zhou, 州) that became the first region that could be called China (Figure 2). So appreciative of his engineering work and diligence, King Shun passed the throne to $\mathrm{Yu}$, who would establish the first dynasty in China, taking up the surname Hsia (Xia, 夏).

In engineering and hydrodynamics, separating a flow into 2 optimized paths can improve flow efficiency, balance distribution, and reduce turbulence and shear stress. ${ }^{1}$ First introduced by the Stanford group and later modified by the Emory/Georgia Tech group, adaptation of the Ygraft to replace the extracardiac conduit in total cavopulmonary connection (TCPC) was proposed to carry the dual advantages of reducing power loss and guaranteeing equal distribution of inferior venous flow, and by inference hepatic factors, to the right and left lungs. ${ }^{2,3}$ The Stanford group has advocated a customized Y-graft that is optimized to each patient's specific anatomy and geometry, whereas the Emory group has chosen

*A strong possibility, but without level 1 evidence, exists that the author and Yu may be related.

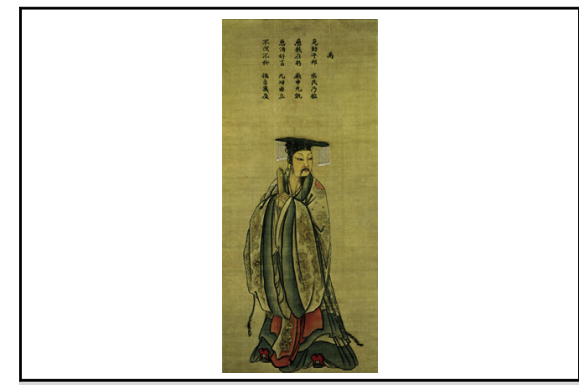

Yu the Great, first Emperor of the Hsia Dynasty of China.

\section{Central Message}

The Emory Y-graft TCPC does not achieve superior hemodynamic performance or better hepatic factor distribution than the standard extracardiac or lateral tunnel TCPC.

See Article page 1529.

commercially available bifurcating grafts such as those used for aorto-iliac grafting. Encouraging computational modeling data at both institutions have led to separate

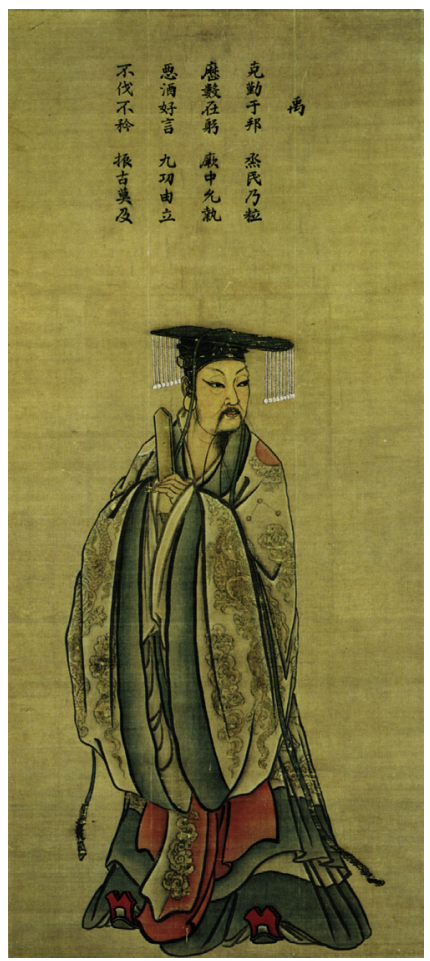

FIGURE 1. Yu the Great, first Emperor of the Hsia Dynasty of China. 


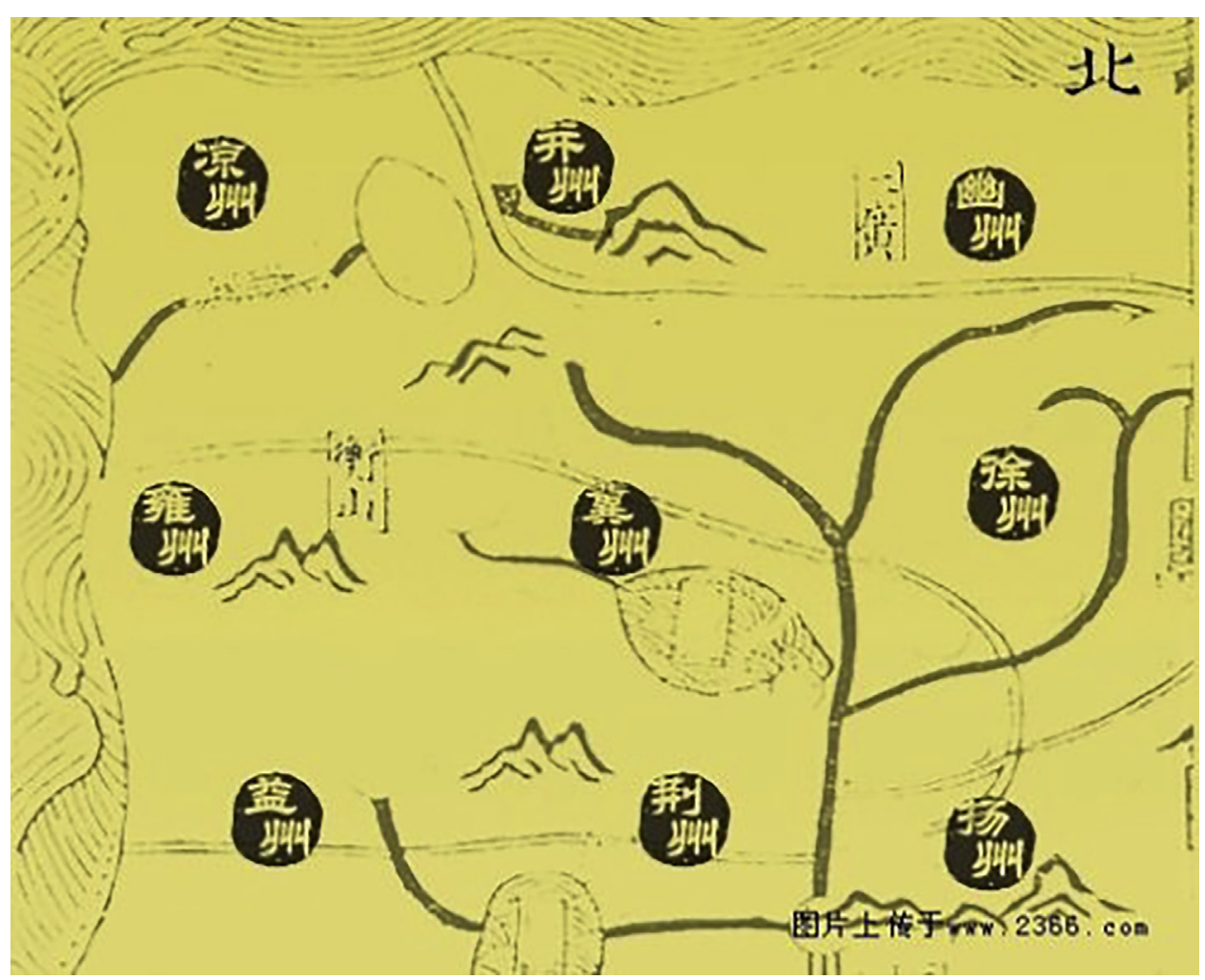

FIGURE 2. Nine Province (Zhou, 州) map showing Y-like diversions of the Yellow River tributaries.

clinical implementation of the Y-graft in TCPC completions. However, at both institutions, clinical experiences with the Y-graft have been mixed. Although the Stanford group seems to have suspended the Y-graft after initial experience of 6 patients that was beset by 1 case of thrombosis and uneven flow dynamics, the Emory group has carried on with 1 single surgeon.

In this issue of the Journal, the Emory group demonstrated no reproducible performance advantages with the Y-graft in 30 patients. ${ }^{4,5}$ In fact, the hemodynamic and flow dynamic outcomes of the Emory Y-graft were highly unpredictable and maybe inferior to the standard extracardiac conduit TCPC. Although there remain important methodological shortcomings (eg, neglecting the influence of the global cardiopulmonary circulation and the numerous mathematical limitations) and vexing heterogeneity between the control and study groups, the article does add to the present state of knowledge regarding the use of Y-graft in TCPC. This is particularly pertinent in context of the recent J. Maxwell Chamberlain Memorial Paper at the Society of Thoracic Surgeons 52nd meeting in Phoenix, Arizona, where Dr Kirk Kanter described acceptable early and intermediate clinical experiences with the Y-graft in 45 patients. In that presentation, the data of which hopefully will be published in due course, no operative mortality was reported, but there was a 38\% rate of readmission for pleural effusion and 2 postoperative deaths. In light of the present study, the obvious question remains whether those 45 patients would have had equivalent or better outcomes if the simpler extracardiac conduit TCPC had been used. Putting it all together, the logical interpretation is that although the Emory Y-graft can be technically performed to achieve satisfactory short-term results, the primary rationale for its use (ie, lower power loss and better inferior venous flow distribution into the lungs) cannot be reliably achieved. In the end, there does not seem to be an overarching impetus to adopt the Emory (or commercial) Y-graft in TCPC completion. Whether this inference also holds true for the customized Y-graft will require future reports from the Stanford group.

Going back to the Great Yu, despite his initial success at taming the Yellow River by series of Y-graft-like diversions and canal building, destructive flooding of the Yellow River continued throughout Chinese history, overflowing its banks 1593 times in the last 3000 to 4000 years, with the last major devastation in 1958 .

\section{References}

1. Yang W, Feinstein JA, Shadden SC, Vignon-Clementel IE, Marsden AL. Optimization of a Y-graft design for improved hepatic flow distribution in the Fontan circulation. J Biomech Eng. 2013;135:011002. 
2. Marsden AL, Bernstein AJ, Reddy VM, Shadden SC, Spilker RL, Chan FP, et al. Evaluation of a novel Y-shaped extracardiac Fontan baffle using computational fluid dynamics. J Thorac Cardiovasc Surg. 2009;137: 394-403.e2.

3. Haggerty CM, Kanter KR, Restrepo M, de Zélicourt DA, Parks WJ, Rossignac J, et al. Simulating 407 hemodynamics of the Fontan Y graft based on patient-specific in vivo connections. J Thorac Cardiovasc Surg. 2013;145:663-70.
4. Martin MH, Feinstein JA, Chan FP, Marsden AL, Yang W, Reddy VM. Technical feasibility and intermediate outcomes of using a handcrafted, area-preserving, bifurcated Y-graft modification of the Fontan procedure. J Thorac Cardiovasc Surg. 2015;149:239-45.e1.

5. Trusty PM, Restrepo M, Kanter KR, Yoganathan AP, Fogel MA, Slesnick TC Pulsatile hemodynamic evaluation of the bifurcated Y-graft Fontan modification and comparison to the lateral tunnel and extracardiac conduits. J Thorac Cardiovasc Surg. 2016;151:1529-36.

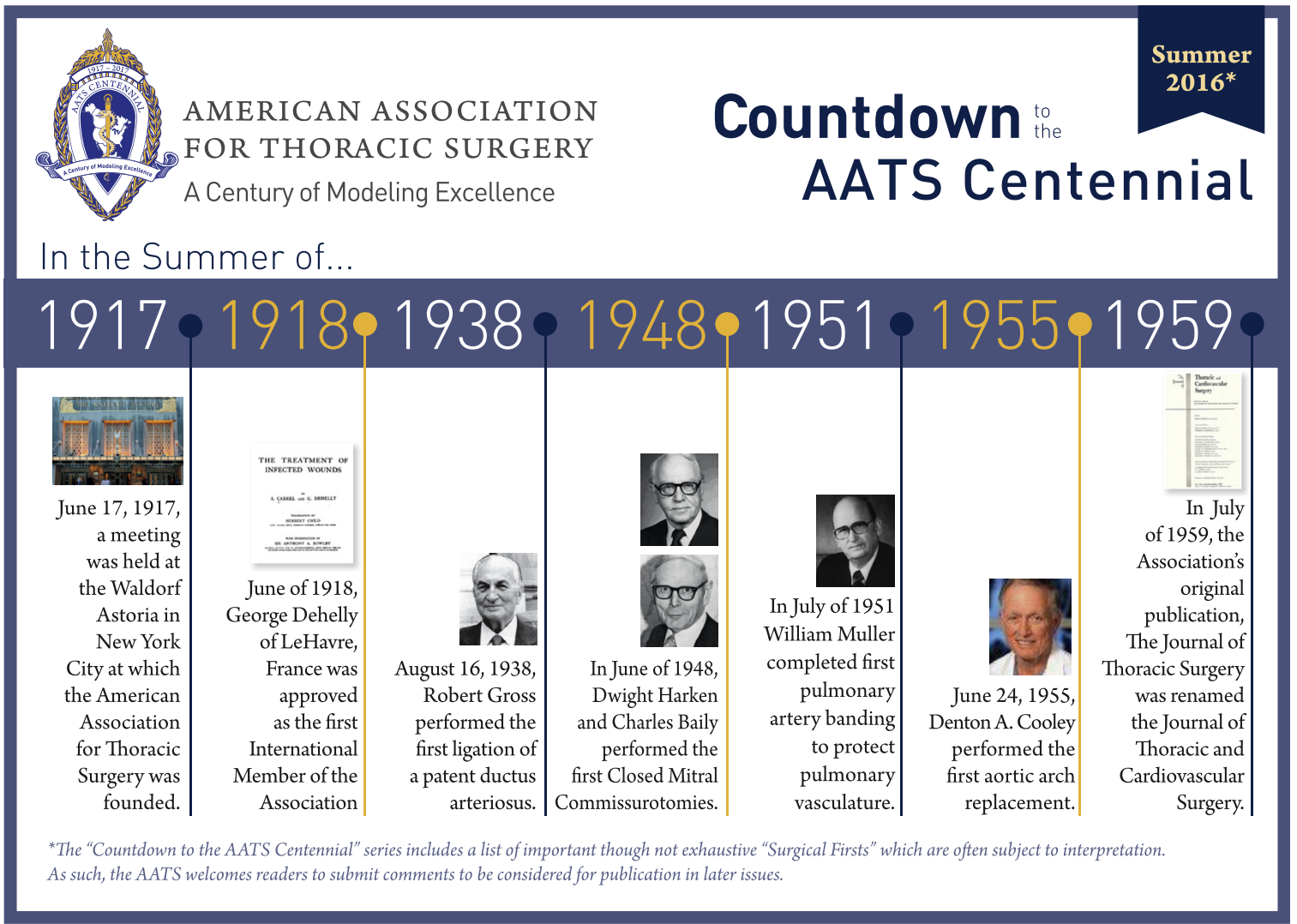

